\title{
Clustering in the biotechnology industry
}

\author{
Stuart O. Schweitzer* and Judith Connell \\ Department of Health Services, UCLA School of Public Health, \\ Los Angeles, CA 90095, USA \\ Fax: $3108253317 \quad$ E-mail: sschweit@ucla.edu \\ ${ }^{*}$ Corresponding author
}

\section{Fredric P. Schoenberg}

Department of Statistics, UCLA School of Public Health, Los Angeles, USA

\begin{abstract}
This study uses Poisson regression techniques to analyse the location of biotechnology companies throughout the USA. Three hypotheses are considered: that firms locate in population centres in order to attract workers, that they locate near colleges and universities where potential workers are likely to be better educated, and that they locate in close proximity to research-oriented universities and institutes because high-technology firms frequently spin-off from these research centres. We find that clusters do tend to be located near population centres colleges and universities but the influence of research-based universities is particularly striking. This highlights a powerful policy instrument for regions hoping to promote high-tech industrial clusters: the creation and maintenance of a first-rate research-oriented university. While these ideas have been suggested in the past, our approach to defining, measuring, and analysing these variables provides new insights into their significance, and also suggests avenues for future research.
\end{abstract}

Keywords: biotechnology; industrial clusters; firm location.

JEL Classifications: R38; I18; L65.

Reference to this paper should be made as follows: Schweitzer, S.O., Connell, J. and Schoenberg, F.P. (xxxx) 'Clustering in the biotechnology industry', Int. J. Healthcare Technology and Management, Vol. x, No. x, pp.xx-xxx.

Biographical notes: AUTHOR PLEASE PROVIDE ABOUT 100 WORDS OF CAREER HISTORY FOR ALL AUTHORS.

\section{Introduction}

Strenuous efforts are being made by national and regional governments throughout the world to attract high-technology industry. The most exciting of these developments are attempts to create high-technology industrial clusters, modelled after California's Silicon Valley or Massachusetts' Route 128 corridor. Unfortunately, however, many questions remain unanswered in terms of which variables and policies influence decisions of high-tech firm location decisions. 
Understanding the location decisions of firms has been one of the most important issues in industrial policy for centuries. Traditionally, the field has considered the location of industrial firms in the manufacturing sector. The propensity of firms to locate near one another has been noted for many years. These earliest clusters typically could be understood in terms of location of natural resources. Steel refineries located near sources of raw materials, such as coal and iron ore, and furniture manufacturers located near sources of lumber. For other industries, access to transportation has been critical. Automobile plants located in port cities, and firms in other industries located near airports, rail, or highway junctions; where climate favoured a particular production process; or in areas that were centres of political activity.

The 'new economy' industries of the latter part of the 20th and 21st centuries are knowledge-based, and it would appear that the old justifications for clusters no longer apply (see Schweitzer and Di Tommaso, 2003). With the value of both inputs and outputs so high in terms of value per unit of size or weight, transportation costs have largely been eliminated as important considerations. In fact, output may not be physical at all, but rather intellectual in nature, so that 'commerce' consists more in transfer of digitised information over the internet than it does in sending actual physical outputs. With these new industries, how do old predictors of clusters apply?

This paper attempts to describe how firms on one new industry, biotechnology, decide on plant location. Armed with better information on how firms locate, governments will be better able to take measures that can encourage firms to locate in particular areas. This information will be useful to all levels of aggregation, from localities, to regions, to national governments.

\section{Background}

The Health Industry Model (Di Tommaso and Schweitzer, 2003) describes the health system as consisting of three components: providers, payers, and manufacturers. In some countries, these roles are combined, especially in countries with socialised health systems combining providers and payers. The traditional view of health systems is that their objectives are limited to the provision of an acceptable level of care at minimal cost. Systems, especially in democracies, are sensitive to demands by populations that health care be maintained at an acceptable level, but these same populations recognise that national resources are limited and so in some countries health systems are particularly frugal in terms of allocation of national income to support the health system. Other systems particularly that of the USA, appear to reflect national tastes for higher levels of access and expenditure.

Another way of describing health systems, discussed by Di Tommaso and Schweitzer (2003), is the extent to which they support an active research and development sector related to medical technology. Medical equipment, pharmaceuticals, and biotechnology are three examples of industries that are especially prominent in some industrialised countries but are less so in others.

The Health Industry Model points out economic advantages that the health industry and other high-technology industries bring to economies, in terms of scientific spill-over from one industry to another, creating wealth through expansion of high-wage and high-profit firms, and participating in the increasingly interconnected world economy in which health services, medical technology, and even patients, themselves, become part of

Author: Please check whether the year of publication is '2003' or ' 2000 '. 
international trade (see Zucker et al., 1999; Porter, 1990; Patel, 1995). These attractions have lead many industrialised countries to try to develop policies that will encourage growth of high-technology industrial sectors. In some cases the hope is that indigenous firms will start up, and in other cases there are attempts to attract foreign firms to establish themselves in particular localities. In general, many countries are trying to create their own 'Silicon Valley' (see Farris et al., 2001). This paper sets out a framework to test various hypotheses concerning where high-technology firms locate. In so doing, policy instruments are described that might be useful for countries (and sub-national units such as regions) to employ, to attract new firms or encourage the growth of existing firms in some of these industries (see Enright, 1996).

An important dimension of firm location is agglomeration, or clustering. There is extensive literature on clustering of firms (see Krugman, 1991). Two themes present themselves. The first is that there are natural factors that draw particular firms to particular areas (Marshall, 1920). These factors may be national resources, ease of transportation, or location of either supply or product markets.

The second theme describes synergies among firms, and describes how firms cluster together to achieve 'economies of agglomeration' (see Greis et al., 1995). These synergies may be rooted in the labour market for particular kinds of workers, the need to reduce search costs by consumers, or the desire by firms to integrate (or cooperate) either vertically or horizontally to lower costs or raise product quality. These linkages between firms seeking complementarities have been especially pronounced in Italy, and have enabled small and medium-size firms to compete globally with far larger firms. This synergy model may explain why firms follow a leader to a particular location, but it is unable to explain why the leader firm first decided to locate in a particular place. And all of these models seem inadequate to explain location of the 'new economy' industries that are particularly knowledge-intensive. Natural resources are irrelevant. And because of the peculiar nature of the products produced by high-technology firms, even transportation costs are so low as to be insignificant in the production and distribution process.

One irony is that some of the industries in this 'new economy' are so well-connected by the internet to one another, to firms that produce their inputs, and to their customers, that to some it seems surprising that these firms benefit at all from physical clustering (Stiglitz, 1999). One might hypothesise that these firms might function equally well if they were located at opposite ends of the Earth from one another. And yet, high-technology clusters occur throughout the world (Swann and Prevezer, 1996). Why is this? To answer this question, we look first at the life-cycle of firms in one particular industry, biotechnology.

\subsection{The life-cycle of biotechnology firms}

One can make inferences about the location of biotechnology firms by understanding how many of these firms were created. Biotechnology firms are frequently started as spin-offs from universities (Audretsch and Stephan, 1996). Biotech start-ups represent the combined talents of a scientist, a source of capital, and management expertise. It is common, especially in the USA that a venture capitalist will literally ask academic scientists if they have any ideas that are ready for product development. If so, negotiations are held that may result in the creation of a new enterprise. With this 
scenario, it is not unusual for the newly created firm to be located close to the university where the scientist continues his or her faculty association.

This scenario illustrates several important aspects of high-technology firms. The first is that the ideas come from university or research centre laboratories. The firm represents the transition from basic research to applied research where products are developed (McMillan et al., 2000). This illustrates the difference in role between non-profit research centres where basic research is conducted, often at government expense, and for-profit enterprises where applied, developmental research is conducted, often funded by investors (Narin et al., 1997; Deeds and Hill, 1997). This approach differs from some other models of firm creation, including that by Zucker and Darby (1996), who have studied the relationship between firm creation and particular 'star' scientists.

The scenario also demonstrates the importance of capital. Frequently the principals in the firm are paid little in cash, but are paid principally in equity interest in the venture. Other costs, however, are real and must be met by actual cash. Venture capital and private placement funds are useful mechanisms for raising this initial capital, because they tend to be non-bureaucratic and geographically mobile. This need for capital and the vital role of venture capitalists suggests another reason for agglomeration - the spatial economies resulting from easier access to venture capital firms (see Powell et al., 2002).

\subsection{Where does the biotech firm locate?}

According to traditional theories of firm location, one could hypothesise that biotech firms would locate near population centres, where the labour force is most abundant. This is a sort of null-hypothesis for our analysis because it says little about the particular nature of high-tech industries and firms. It suggests merely that the firms would locate where workers are, just as other firms do, at least where there are no particular natural factors (ports, highways, natural resources, etc.) altering the picture.

But high-technology firms in general and biotech firms in particular, are different. They rely on information and uniquely skilled personnel - not a typical cross-section of worker skills (Ernst and Young, 1998). This implies that a biotech firm would locate near sources of scientifically-skilled personnel, perhaps near colleges and universities, and not necessarily near population centres.

This hypothesis might not be specific enough, however. Our life-cycle scenario suggests that the firm's initial key employee comes from a university or research institute, and is likely to retain ties to that institution. In the beginning, the need is simple - the person must retain the academic appointment in order to continue the line of basic research and to retain a salary while other compensation from the start-up firm is merely speculative ownership shares. The university also provides other key scientific workers in the form of graduates or even graduate students. Thus a modification of the location hypothesis would be that biotech firms locate near research-oriented universities and institutions, not near educational institutions in general.

A cursory look at other industries suggests yet another hypothesis concerning the location of firms. Many firms in some industries are spin-offs, or derivatives, of existing firms (Pisano, 1991). An example is the pharmaceutical industry, which derived from the chemical industry. In fact, prior to World War II, pharmaceuticals were little more than purified chemicals produced and sold to pharmacists who compounded them and packaged them into forms that could be taken conveniently by patients, according to 
physician orders. If one looks at pharmaceutical firms in the USA today, one sees that many of them are located in the mid-Atlantic states, especially New Jersey and Delaware, where the chemical industry first grew in the 19th century. Taking this as a model, one might hypothesise that biotechnology firms are mere spin-offs from pharmaceutical firms and so they would tend to be located near major pharmaceutical firms. But this model of biotech firm development fails to capture the essential differences in scientific basis and paradigm between pharmaceuticals and biotechnology (Liebeskind et al., 1996). A closer observation of biotech firms shows that they grew independent of pharmaceutical firms, though a welter of mergers in recent years has brought them together, at least in terms of corporate ownership.

\subsection{Two perspectives on firm location}

To better understand the factors determining the location of high-technology firms, there are two perspectives that can be employed. We call the first the 'County Manager' view. This is the view used by regions as they attempt to attract high technology firms. There are various policy instruments at the disposal of a regional government. Examples include property tax forgiveness and concessions to subsidise construction costs, relaxation of planning or environmental regulations, and construction of highways, rail lines, internet links, and other utility services. All of these have been used in the past to attract firms to particular cities, counties, or regions.

A second perspective on the location decision is called the 'entrepreneurial' view. This is the perspective of the scientist-entrepreneur who could begin a start-up company and, if so, must decide where to locate the firm. The entrepreneurial view focuses on things that are key to the decision-maker's willingness to start a spin-off enterprise such as favourable university policies and availability of capital. The two views overlap, of course, as the entrepreneur certainly needs to consider the cost of establishing a firm in a particular area, and economies that result from proximity to other resources and firms. Our analysis is based primarily on this entrepreneurial perspective.

\section{Methodology}

We use Poisson multiple regression analysis to explain the degree to which firm location is dependent upon several independent variables related to the location decision. The multiple regression models relate the number of biotechnology firms in a zip code to various characteristics of that zip code: pop $_{i}$ (the population in zip code i), $\mathrm{dcu}_{\mathrm{i}}$ (the distance between zip code ${ }_{i}$ and the nearest college or university), dru $_{i}$ (the distance between zip code $\mathrm{i}_{\mathrm{i}}$ and the nearest research university), and $\mathrm{fru}_{\mathrm{i}}$ (is the level of funding of the nearest research university to zip code $\mathrm{i}_{\mathrm{i}}$ ).

In fitting our data to such a model by ordinary least squares, one typically assumes that the errors are normally distributed, which clearly cannot be the case here since the observations of the dependent variable (the number of firms in a zip code) are always non-negative integers and, in most cases, zero. We therefore use Poisson, rather than least squares, regression. Poisson regression is commonly used for regressions involving a dependent variable that is a count, as in this case (Green, 1993). The underlying assumption is that the dependent variable follows a Poisson distribution, which would be the case if for example, each firm is distributed independently of the others and with a 
common spatial distribution. This Poisson assumption is often a reasonable first approximation for count data (Sen and Srivastava, 1990). ${ }^{1}$

\section{Data}

The study is based on an aggregated listing of the US' biotechnology firms, colleges and universities. The location of all entities was determined by zip code which was the study's geographic unit. Zip codes showing no population in the 2000 census estimate were not included. We compiled a database of 1,177 biotech firms, 1,573 colleges and universities, and a subset of 396 research universities.

\subsection{Biotechnology companies}

The list of biotechnology firms came from the 2000 Nature Biotechnology Directory and Buyers' Guide Online, a listing of organisations, product and service providers in the biotechnology industry. It is produced in association with Nature Publishing Group Reference, publishers of The Biotechnology Directory, The Biotechnology Guide USA, and Nature Biotechnology, and can be found at www.guide.nature.com.

The companies were self-defined through membership or self-selection. The directories are broad in scope incorporating a variety of classifications such as genetics, diagnostics and therapeutics, molecular biology, immunology and microbial products and services. In addition to active research companies, the lists include suppliers and testers used by these companies. Pharmaceutical companies were not included but no exclusions were made for subsidiary biotechnology firms. We eliminated all companies that were in the agricultural, veterinary, and environmental products and services group, but we had no other exclusion criteria.

\subsection{Universities}

The source for names and zip codes of colleges and universities in the USA was a comprehensive listing compiled by the University of Texas at the Austin web site, (www.utexas.edu) which contains a list of regionally accredited 4-year US colleges and universities in 2000. Zip codes not included in the University of Texas directory were identified from individual institution websites.

\subsection{Research universities}

Research universities were identified in two ways:

- designation

- research activity.

Designation as a research-funded university was based on participation in the 2000 National Science Foundation (NSF) Survey of Research and Development Expenditures at Universities and Colleges, which has been conducted annually since 1972 . The population of institutions surveyed in most years consisted of the 500-700 universities and colleges that currently had doctoral programs in science or engineering 
fields, or annually performed at least $\$ 50,000$ in separately budgeted research and development (SBRD). Separately budgeted R\&D is defined as current fund expenditures designed to produce specific research outcomes and either funded by a government or private agency external to an academic institution or separately budgeted by an internal unit of an institution. These institutions have traditionally received more than $95 \%$ of US academic R\&D funds.

The level of research activity was the amount of individual school funding reported in the survey's Academic Institutional Profiles for the fiscal year 1998. Our data is drawn from the life sciences component of the survey, which is the sum of 'Agricultural sciences', 'Biological sciences', 'Medical sciences', and 'Other, not elsewhere classified'. For our purposes, we excluded agricultural sciences. R\&D expenditures at 615 qualifying universities and colleges in the fiscal year 1998 totalled $\$ 12.5$ billion. The range for individual institutions was $\$ 10,000-400$ million with a mean of $\$ 26.2$ million and a median of $\$ 1$ million. We defined a 'research university' as one reporting at least \$20 million in SBRD during calendar year 1998, which represented the top quartile of all reporting universities.

\section{Results}

The results of the regression estimation are shown in Table 1. The dependent variable for each of the six regressions is the number of biotech companies in a particular zip code. Pop is the population residing in that zip code. Distances between biotechnology firms and

- $\quad$ each zip code's population (pop)

- the closest college or university (dcu)

- the closest research university (dru)

are derived from the ArcGIS computer mapping software program, utilising the zip code of each firm and college or university.

Table 1 Results of the Poisson regressions predicting the likelihood of a biotech firm in a zip code

\begin{tabular}{|c|c|c|c|c|c|}
\hline \multicolumn{2}{|c|}{ Model } & \multirow{2}{*}{$\frac{\text { Coefficient }}{-4.241}$} & \multirow{2}{*}{$\frac{\text { Std error }}{3.908 \times 10^{-2}}$} & \multirow{2}{*}{$\frac{z \text {-statistic }}{-108.52}$} & \multirow{2}{*}{$\frac{p}{<2 \times 10^{-16}}$} \\
\hline 1 & Intercept & & & & \\
\hline & pop & $1.387 \times 10^{4}$ & $2.784 \times 10^{2}$ & 49.83 & $<2 \times 10^{-16}$ \\
\hline & $\mathrm{AIC}=11, \mathrm{C}$ & & & & \\
\hline & $\mathrm{R}^{2}=0.130$ & & & & \\
\hline \multirow[t]{5}{*}{2} & Intercept & -3.056 & $5.237 \times 10^{-2}$ & -58.35 & $<2 \times 10^{-16}$ \\
\hline & pop & $1.063 \times 10^{4}$ & $3.183 \times 10^{2}$ & 33.38 & $<2 \times 10^{-16}$ \\
\hline & $\mathrm{dcu}$ & $-7.285 \times 10^{2}$ & $3.550 \times 10^{-3}$ & -20.52 & $<2 \times 10^{-16}$ \\
\hline & $\mathrm{AIC}=10,2$ & & & & \\
\hline & $\mathrm{R}^{2}=0.204$ & & & & \\
\hline
\end{tabular}


Table 1 Results of the Poisson regressions predicting the likelihood of a biotech firm in a zip code (continued)

\begin{tabular}{|c|c|c|c|c|c|}
\hline \multicolumn{2}{|c|}{ Model } & \multirow{2}{*}{$\begin{array}{c}\text { Coefficient } \\
-2.680\end{array}$} & \multirow{2}{*}{$\frac{\text { Std error }}{5.400 \times 10^{-2}}$} & \multirow{2}{*}{$\frac{z \text {-statistic }}{-49.31}$} & \multirow{2}{*}{$\frac{p}{<2 \times 10^{-16}}$} \\
\hline 3 & Intercept & & & & \\
\hline & pop & $9.805 \times 10^{3}$ & $3.200 \times 10^{2}$ & 30.70 & $<2 \times 10^{-16}$ \\
\hline & dru & $-2.300 \times 10^{-2}$ & $9.773 \times 10^{-4}$ & -23.92 & $<2 \times 10^{-16}$ \\
\hline & $\mathrm{AIC}=9,846$ & & & & \\
\hline & $\mathrm{R}^{2}=0.242$ & & & & \\
\hline \multirow[t]{6}{*}{4} & Intercept & -2.386 & $5.610 \times 10^{-2}$ & -42.53 & $<2 \times 10^{-16}$ \\
\hline & pop & $9.159 \times 10^{3}$ & $3.212 \times 10^{2}$ & 28.51 & $<2 \times 10^{-16}$ \\
\hline & dcu & $-4.835 \times 10^{-2}$ & $3.885 \times 10^{-3}$ & -12.45 & $<2 \times 10^{-16}$ \\
\hline & dru & $-1.611 \times 10^{-2}$ & $9.248 \times 10^{-4}$ & -17.42 & $<2 \times 10^{-16}$ \\
\hline & $\mathrm{AIC}=9,650$ & & & & \\
\hline & $\mathrm{R}^{2}=0.259$ & & & & \\
\hline \multirow[t]{6}{*}{5} & Intercept & -3.196 & $7.167 \times 10^{-2}$ & -44.59 & $<2 \times 10^{-16}$ \\
\hline & pop & $9.696 \times 10^{3}$ & $3.227 \times 10^{2}$ & 30.05 & $<2 \times 10^{-16}$ \\
\hline & dru & $-2.292 \times 10^{-2}$ & $9.514 \times 10^{-4}$ & -24.10 & $<2 \times 10^{-16}$ \\
\hline & fru & $3.991 \times 10^{-6}$ & $3.188 \times 10^{-7}$ & 12.52 & $<2 \times 10^{-16}$ \\
\hline & $\mathrm{AIC}=9,708$ & & & & \\
\hline & $\mathrm{R}^{2}=0.254$ & & & & \\
\hline \multirow[t]{7}{*}{6} & Intercept & -2876 & $7.354 \times 10^{-2}$ & -39.11 & $<2 \times 10^{-16}$ \\
\hline & pop & $9.098 \times 10^{3}$ & $3.240 \times 10^{2}$ & 28.08 & $<2 \times 10^{-16}$ \\
\hline & dcu & $-4.675 \times 10^{-2}$ & $3.832 \times 10^{-3}$ & -12.20 & $<2 \times 10^{-16}$ \\
\hline & dru & $-1.592 \times 10^{-2}$ & $2.250 \times 10^{-3}$ & -12.60 & $<2 \times 10^{-16}$ \\
\hline & fru & $5.568 \times 10^{-6}$ & $2.659 \times 10^{-7}$ & 20.94 & $<2 \times 10^{-16}$ \\
\hline & $\mathrm{AIC}=9,613$ & & & & \\
\hline & $\mathrm{R}^{2}=0.270$ & & & & \\
\hline
\end{tabular}

For each parameter estimate we show the standard error, the z-statistic, and the $p$ value. Two measures of the overall goodness of fit for the Poisson regression are calculated. The first is the Akaike Information Criterion, AIC. The lower the AIC, the better is the goodness of fit of the regressions. The AIC adjusts for the number of parameters being estimated. The second measure is the $\mathrm{R}^{2}$, the proportion of variance of the dependent variable explained by the regression. This is calculated as 1-(residual variation/null variation).

The model estimates show that all of the variables in the model are highly significant, so that a model that is constructed using only population to predict the location of biotech firms would be omitting significant variables, and hence would be an incorrect specification. The location of a nearby college or university, the location of a nearby research university, and the level of funding of a nearby research university are all important predictors of the likelihood of a biotech firm being in a particular zip code. All of the coefficients have the expected sign, with higher population increasing the 
likelihood that a biotech firm will be located in an area, and distance from a zip code to the nearest college or university, or research university both reducing the likelihood. The influence of research funding is positive. The AIC and the $\mathrm{R}^{2}$ for the models indicate that the goodness of fit improves when proximity to colleges and universities is included in the model, and it improves still further with the inclusion of proximity of research universities. Proximity to a research university is a more important predictor than proximity to a college or university, as seen by comparing model 3 with model 2 . The coefficient of research funding is highly significant, and its inclusion improves the regression fit (model 5 compared to model 3).

Model 4 includes as independent variables both the distance to the closest college or university (dcu) and also the distance to the nearest research university (dru). When dru enters the equation in model 4 , the importance of dcu falls, as one sees in comparing model 4 with model 2 . Not only does the coefficient of dcu fall, but its standard error rises and its z-statistic falls. This suggests that the importance of a nearby college or university, while a strong predictor of the location of a biotech firm, is - to some extent - superseded by the proximity of a research-oriented university.

A similar comparison can be made with the coefficient of the research funding at the nearest research university (fru) in model 5 compared with model 3. As important as fru is in model 5 (lowering AIC and raising $\mathrm{R}^{2}$ ), the coefficient of dru (and its se and Z-statistic) changes very little. In other words, being in the proximity of a university that is classified as a research university is important (model 3). All research universities are not the same, however. The size of that university's research program matters to a great degree.

One might suspect that multicollinearity would be a problem, as there could be high correlation between pairs of independent variables, such as population and presence of a college or a university, or between the location of a college or university and that of a research university. Table 2 shows the correlation matrix for our independent variables.

Table 2 Correlation matrix

Author: Please check if this entry is correct.

\begin{tabular}{lllll}
\hline & pop & $d c u$ & $d r u$ & fru \\
\hline pop & 1 & 0.168 & 0.146 & -0.023 \\
dcu & 0.168 & 1 & 0.690 & 0.95 \\
dru & 0.146 & 0.690 & 1 & 1.113 \\
fru & -0. & 0.045 & 0.113 & 1 \\
\hline
\end{tabular}

Most of the coefficients of correlation are quite small, suggesting that multicollinearity may not be a particularly severe problem. The only independent variables that are relatively highly correlated with one another are dru and dcu. This correlation falls to 0.181 , however, for zip codes $<50 \mathrm{~km}$ from a college or university $(32,946$ out of 41,717 zip-codes), and falls still further, to 0.007 , for a distance less than $10 \mathrm{~km}(12,151$ zip codes out of 41,717), suggesting that the high correlation shown in Table 2 is the result of a large number of empty zip-codes with neither a college or a university nor a research university nearby. The correlation coefficient $(\rho)$ between population (pop) and $\mathrm{dcu}$ is $\rho=-0.067$, which is consistent with the observation that there are many colleges, and even research universities, that are not located in major metropolitan areas. 
The results are consistent with our hypotheses that predictions of biotech firm location improve as one goes from the population model (model 1) to the model that incorporates proximity of colleges and universities (model 2), to the model that incorporates proximity of research universities (model 3), and, finally, to the model that incorporates level of research funding (model 4).

\section{Discussion}

Observational analyses showing associations can never directly infer causality, but with a strong theoretical reasoning behind our results, it is reasonable to impute policy implications to our findings. Our findings suggest that biotechnology firms tend to locate in populated areas, as one might expect. This is consistent with the simple model that biotech firms locate where there is a pool of workers from which to hire. But the striking part of our analysis is that the model improves markedly when we include the influence of the proximity of colleges and universities. This is consistent with the idea that biotechnology firms do not hire so much from a general population reservoir, but rather from a pool of college students or graduates. The model is an even better predictor when we include universities that are especially rich in terms of a research environment, measured either as being one of the 'elite' research institutions (in terms of government and private extramural funding), or in terms of the level of such support.

The importance of research universities can be interpreted in two ways, according to two different models of how it is that biotechnology firms locate where they do. The first is the 'spin-off' model, which says that firms are created by some sort of splitting-off of faculty (and graduate students) from a research university. But not all biotechnology firms are university spin-offs. Some represent the location decision of either new firms that have no relationship to the near-by research university, or they are the relocation of an already-existing biotechnology firm. In either case when existing firms locate near research universities, it is reasonable to hypothesise that they seek access to the highly trained labour force that is already in the area. This is a kind of analogue to the old clustering model in which firms locate near some kind of natural resource. In this case the 'natural resource' is a labour force that is associated with a research-oriented university.

These findings are important for any country, region, or locality that would like to develop its biotechnology industry: that firms in this industry tend to be located near research-oriented universities. A policy instrument for governments is clearly suggested: a precondition to the development of a strong biotechnology industry is a strong university capacity in the basic sciences that form the foundation for product development. Because of the similarities between all knowledge-intensive industries, including not only biotechnology, but also aerospace, electronics, telecoms, computers, and dot-coms it is likely that a strong research university capacity is equally important for the development of these other industries. It is possible, though not tested in this project, that these industries are synergistic with biotechnology. One test of this hypothesis is whether or not high-technology clusters tend to be comprised of firms in a single industry (such as biotech) or, rather, a number of knowledge-intensive industries. This is a fruitful question for further investigation. 


\section{Conclusions}

Our study, though suggestive of important relationships determining the location of biotechnology firms, must be interpreted cautiously.

- an observational study cannot demonstrate causality

- $\quad$ other models should be tested along-side the models we have estimated.

Even within our models, there may be important confounding variables that would change our results, if they were included.

The location of high technology industries is different from that of more traditional manufacturing firms, and these differences suggest a different set of policy instruments that can be used by localities and national governments to attract these firms and encourage their creation and growth. Our findings support the idea that the strength of a country's research-oriented universities plays a strong role in determining the vitality of the country's high technology industries.

Our model of high tech spin-offs shows that the strength of the research establishment is unlikely to be sufficient in itself, however, to promote the creation of high-technology firms. There must be a legal framework to support the interests of universities, investors, and individual scientist-entrepreneurs for spin-offs to succeed. Additionally, reimbursement policies must exist to encourage the substantial investment in R\&D that is necessary to bring high technology products, like biotechnology drugs, to market.

Future research can fruitfully explore the effect of universities in other countries, where public sector financing of high-tech centres may be more important than it is in the USA. Our results suggest that there are more biotech firms in close proximity to some research universities than to others. This suggests that universities differ in their ability to generate spin-off enterprises. It is important to better understand university policies that might be used to encourage these spin-offs.

Analysis of firm location is useful in improving our understanding of the life-cycle of firms, as well as suggesting policy instruments for governments desiring to promote biotechnology or other high-technology industries.

\section{References}

Audretsch, D.B. and Stephan, P.E. (1996) 'Company-scientist locational links: the case of biotechnology', American Economic Review, Vol. 86, No. 3, pp.641-652.

Bergman, E.M. and Fesser, E.J. (2000) Industrial and Regional Clusters: Concepts and Comparative Applications, Regional Research institute, West Virginia University, http://www.rri.wvu.edu/WebBook/Bergman-Feser/con-tents.htm. AUTHOR PLEASE PROVIDE CITATION IN TEXT FOR THIS REFERENCE.

Deeds, D., DeCarolis, D. and Coombs, J. (1997) 'The impact of firm specific capabilities on the amount of capital raised in an initial public offering: evidence from the biotechnology industry', Journal of Business Venturing, Vol. 12, No. 1, pp.31-46. AUTHOR PLEASE PROVIDE CITATION IN TEXT FOR THIS REFERENCE.

Deeds, D.L. and Hill, C.W. (1996) 'Strategic alliances and the rate of new product development: an empirical study of entrepreneurial biotechnology firms', Journal of Business Venturing, Vol. 11, pp.41-55. 
Di Tommaso, M.R. and Schweitzer, S.O. (2000) 'L'industria della salute: oltre il contenimento dei costi' (The health industry: more than containing costs) L'Industria: Rivista di economia e politica industriale (Review of Economics and Industrial Policy), Vol. 21, No. 3, pp.403-426. AUTHOR PLEASE CHECK WHETHER THE YEAR OF PUBLICATION IS '2000' OR '2003'.

Enright, M.J. (1996) 'Regional clusters and economic development: a research agenda', in Staber, U.H. et al. (Eds.): Business Networks: Prospects for Regional Development, Walter de Gruyte, Berlin. AUTHOR PLEASE PROVIDE PAGE RANGE.

Ernst and Young, L.L.P. (1998) New Directions 98: The Twelfth Biotechnology Industry Annual Report, Ernst and Young LLP, Palo Alto, CA. AUTHOR: PLEASE PROVIDE SURNAME FOR THE FIRST AUTHOR AND PLEASE PROVIDE PAGE RANGE FOR THIS REFERENCE.

Farris, K.F., Hwang, V. et al. (2001) Heart of Gold: The Bioscience Industry in Southern California, Report by the Los Angeles Regional Technology Alliance. AUTHOR PLEASE PROVIDE PAGE RANGE.

Fransman, M. and Tanaka, S. (1995) 'Government, globalization, and universities in Japanese biotechnology', Research Policy, Vol. 24, pp.13-49. AUTHOR: PLEASE PROVIDE CITATION IN TEXT FOR THIS REFERENCE.

Green, W.H. (1993) Econometric Analysis, 2nd ed., Macmillan Publishing Co., New York. AUTHOR PLEASE PROVIDE PAGE RANGE.

Greis, N.P., Dibner, M.D. and Bean, A.S. (1995) 'External partnering as a response to innovation barriers and global competition in biotechnology', Research Policy, Vol. 24, pp.609-630.

Krugman, P. (1991) Geography and Trade, MIT Press, Cambridge, MA. AUTHOR PLEASE PROVIDE PAGE RANGE.

Liebeskind, J., Oliver, A., Zucker, L. and Brewer, M. (1996) 'Social networks, learning, and flexibility: sourcing scientific knowledge in new biotechnology firms', Organization Science, Vol. 3, pp.783-831.

Marshall, A. (1920) Industry and Trade, Macmillan, London. AUTHOR PLEASE PROVIDE PAGE RANGE.

McMillan, G.S., Narin, F. and Deeds, D. (2000) 'An analysis of the critical role of public science in innovation: the case of biotechnology', Research Policy, Vol. 29, pp.1-8.

Narin, F., Hamilton, K. and Olivastro, D. (1997) 'The increasing linkage between US technology and public science', Research Policy, Vol. 26, pp.317-330.

Patel, P. (1995) 'Localised production of technology for global markets', Cambridge Journal of Economics, Vol. 19, pp.141-153.

Pisano, G. (1991) 'The governance of innovation: vertical integration and collaborative arrangements in the biotechnology industry', Research Policy, Vol. 20, pp.237-249.

Porter, M.E. (1990) The Competitive Advantage of Nations, Free Press, New York. AUTHOR PLEASE PROVIDE PAGE RANGE.

Powell, W.W., Koput, K.W., Bowie, J.I. and Smith-Doerr, L. (2002) 'The spatial clustering of science and capital: accounting for biotech firm-venture capital relationships', Regional Studies, Vol. 36, No. 3, pp.291-305.

Schweitzer, S.O. and Di Tommaso, M.R. (2003) 'Why do biotechnology firms cluster? some possible explanations', in Sugden, R., Cheng, R.H. and Meadows, R. (Eds.): Urban and Regional Prosperity in a Globalized, New Economy, Edward Elgar, Cheltenham and Brookfield. AUTHOR PLEASE PROVIDE PAGE RANGE.

Sen, A. and Srivastava, M. (1990) Regression Analysis: Theory, Methods, and Applications, Springer-Verlag, New York. AUTHOR PLEASE PROVIDE PAGE RANGE.

Stiglitz, J. (1999) 'Public policy for a knowledge economy', Speech for Department for Trade and Industry and Center for Economic Policy Research, London, UK, http://www.worldbank.org/html/extdr/extme/jssp012799a.htm, January 27. 
Swann, P. and Prevezer, M.A. (1996) 'A comparison of the dynamics of industrial clustering in computing and biotechnology', Research Policy, Vol. 25, pp.1139-1157.

Von Hippel, E. (1988) The Sources of Innovation, Oxford University Press, Oxford. AUTHOR PLEASE PROVIDE CITATION IN TEXT AND PLEASE PROVIDE PAGE RANGE FOR THIS REFERENCE.

Zucker, L.G. and Darby, M.R. (1996) 'Star scientists and institutional transformation: patterns of invention and innovation in the formation of the biotechnology industry', Proceedings of the National Academy of Sciences, Vol. 93, No. 23, November 12, pp.12709-12716.

Zucker, L.G., Darby, M.R. and Armstrong, J. (1999) 'Intellectual capital and the firm: the technology of geographically localized knowledge spillovers', National Bureau of Economic Research, Working Paper No. 4946, Cambridge, MA. AUTHOR PLEASE PROVIDE PAGE RANGE.

\section{Note}

${ }^{1}$ An alternative approach is to use a two-part regression model, in which the dependent variable in the first part is dichotomous, namely whether or not a zip code contains at least one firm. In the second part, the dependent variable would be continuous (and $>0$ ), the number of biotech firms in the zip code. Such a model has a weakness in that the first part regression omits useful information on the number of firms that might appear in a zip code. 